\title{
Inheritance of Internode Length and its Relation to Head Exsertion and Head Size in Broccoli
}

\author{
James R. Baggett, Deborah Kean, and Kathryn Kasimor \\ Department of Horticulture, Oregon State University, Agriculture and Life Sciences Building 4017, \\ Cowallis, OR 97331-7304
}

Additional index words. Brassica oleracea, Italica group, vegetable breeding, mechanical harvest

\begin{abstract}
Broccoli (Brassica oleracea L. Italica Group) lines with heads borne above the foliage (exserted) favorably for mechanical harvest were crossed with inbred lines with nonexserted heads. Length of the heads, defined as the portion of the plant above the highest major leaf, was $\approx 50 \%$ of the total plant height in short and tall parents and all plants of the $F_{1}, F_{2}$, and backcross generations. The principal characteristic identified with good head exsertion was long internodes. Internode length was inherited mostly in an additive manner, with some effect of hybrid vigor apparent in the $F_{1}, F_{2}$, and backcross to the tall parent. Plant height was also inherited in an additive manner. Head weight in the high-exsertion parent was much lower than in the low-exsertion parent. Within each parent and the $F_{1}$, head weight was greater in plants with longer internodes and greater plant height. In the segregating generations $\left(F_{2}\right.$ and backcross), head weight increased with decreasing internode length, indicating that selection for high head exsertion would result in smaller heads and reduced yield.
\end{abstract}

Harvesting of broccoli, either by hand or machine, is facilitated by an elongated growth habit that results in the protrusion of the head above the foliage (Fig. 1). This attribute is defined as head exsertion. Plant elongation per se is important because short plants require tiresome stooping by hand harvesters and because of the need to cut heads for either processing or fresh market of a minimum length (i.e., about 15 to $16 \mathrm{~cm}$ ) without including large leaves and the fibrous part of the stem.

Growth habit of broccoli cultivars may be especially important for machine harvest. Walton and Casada (1988) measured head height, cutting height, and head length in broccoli cultivars, along with plant width and density. They found cutting height and head height were related and they considered cultivars with greater head and cutting height superior for once-over mechanical harvest. They also stressed the importance of cutting-height uniformity and a low density canopy, which permitted the heads to be seen easily. A tractor-mounted broccoli harvester and its use on several cultivars were described by Casada et al. (1989). It was noted that when heads were cut low, a large number of leaves remained on the harvested head. When plants were more elongated because of seasonal growth factors, fewer leaves were retained on the cut heads.

The broccoli breeding program at Oregon State Univ. (OSU) has for many years stressed head exsertion. A number of inbred lines with extreme elongation of stems and heads have been developed and used in experimental hybrids. A group of lines released in 1983 included some with moderate exsertion, and several with an extreme tendency for stem elongation (Baggett and Kean, 1985). When used in combination with less exserted in breds, the elongated inbreds substantially increase the head exsertion of $F_{1}$ hybrids. We have observed that exserted broccoli plants tend to develop darker green color of the heads and that there is less fiber in a 15 to $16 \mathrm{~cm}$ cut head than in a similar cut head of a short compact cultivar. Achieving adequate head weight for economical yields in the exserted type has been difficult.

Before the present study, the components of exserted habit in

Received for publication 14 Mar. 1994. Accepted for publication 17 Oct. 1994. Oregon Agricultural Experiment Station technical paper no. 10,440. The cost of publishing this paper was defrayed in part by the payment of page charges. Under postal regulations, this paper therefore must be hereby marked advertisement solely to indicate this fact.
OSU broccoli lines had not been adequately determined. Although it appears in the field that the heads of exserted plants are proportionately longer, overall internode length is obviously important. The purposes of this study were to 1) determine, by studying exserted and more compact parents and their progenies, the relative importance of plant proportion and internode length and determine their inheritance and 2) clarify the association of head weight with head exsertion.

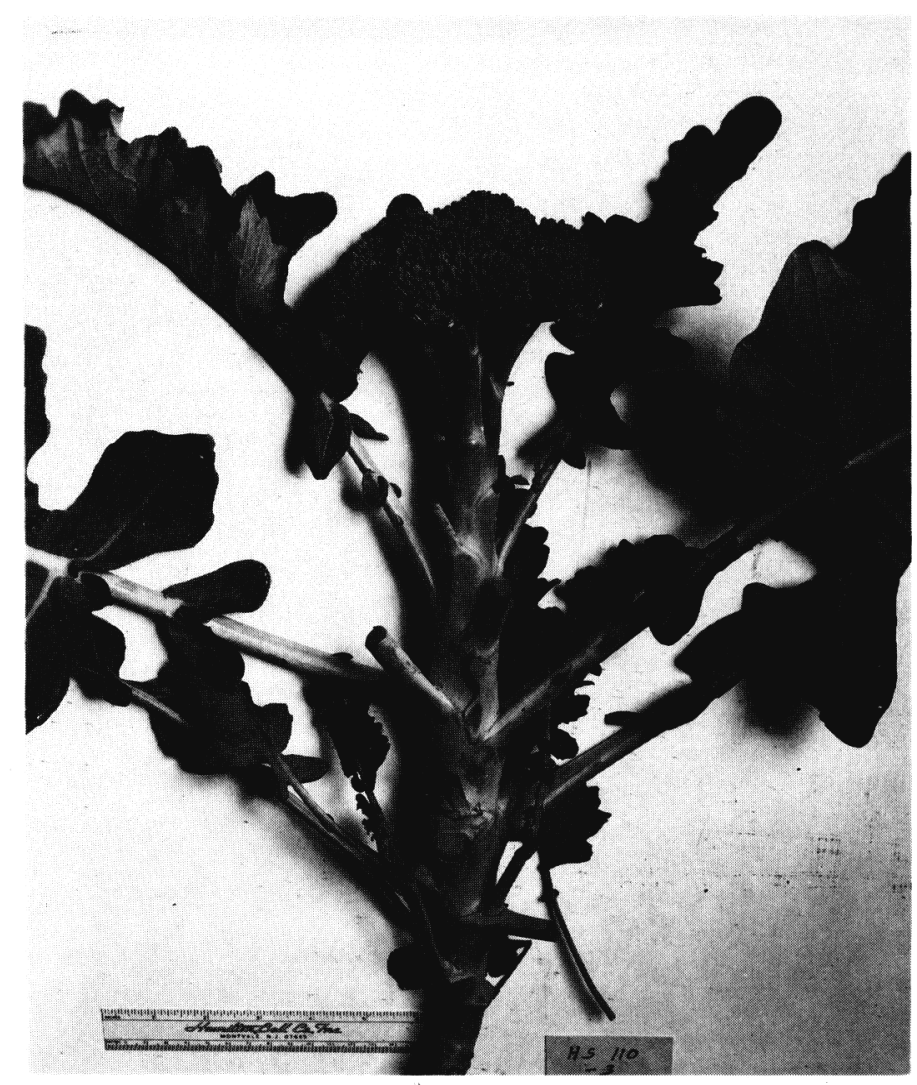

Fig. 1. Growth habit of broccoli line HS110 showing exserted head 


\section{Materials and Methods}

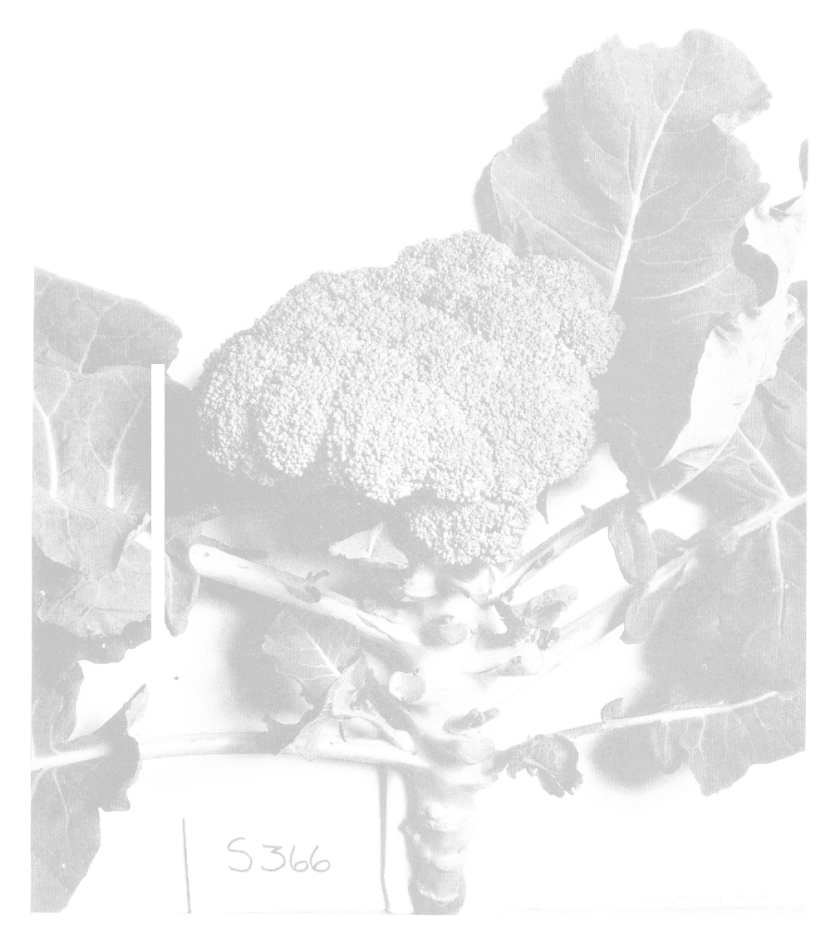

Fig. 2, Growth habit of broccoli line S366 showing compact habit with nonexserted head.
Four uniform OSU inbred broccoli lines, each of which has been maintained by combinations of selfing and sibbing for many years, were used as parents. The exserted parents were HS110 (Fig. 1 ) and HS179, which are early maturing, with long internodes and small to medium-sized heads. Inbred lines S366 (Fig. 2) and S240, which have heavy stems and large heads, were used as the nonexserted parents. S366 is medium early in maturity, while S240 is quite late in maturity. Inbreds S366 and S240 were the least exserted of the inbreds available in our program, but are not as extreme in this characteristic as many commercial broccoli hybrids we have grown $\mathrm{m}$ our trials. The crosses HS110 x S366 and HS 179 x S240 were studied in 1989, and the cross HS179 x S366 was studied in 1992.

Crosses were made in the greenhouse by pollinating emasculated immature flower buds. $\mathrm{F}_{2}$ and backcross seeds were produced by hand pollinations in the greenhouse on plants produced from cuttings of $\mathrm{F}_{2}$ and parent plants grown from seed in the field.

Plant measurements were made in the field in 1989 and 1992. Each year, plants were grown in field seedbeds and transplanted by machine at $\approx 5$ weeks of age into rows that were $0.9 \mathrm{~m}$ apart. Plants were spaced $46 \mathrm{~cm}$ apart in the row. General cultural practices were typical of commercial practices in the area.

In 1989, plant measurements were made on each plant when the first flower opened. This stage was selected because it was expected to provide a precise stage with less chance for variation due to subjective decisions. Plants were measured for total height (ground to top of intforescence) and height of foliar portion of the plant (ground to the attachment of the top main leaf, usually with an axillary bud or branch present). To determine internode length,

Table 1. Generation means ${ }^{2}$ of broccoli plant and head measurements, 1989 and 1992

\begin{tabular}{|c|c|c|c|c|c|c|c|}
\hline Generation $^{y}$ & $\begin{array}{c}\text { No. } \\
\text { plains }\end{array}$ & $\begin{array}{c}\text { Total } \\
\mathrm{hr} \\
(\mathrm{cm})\end{array}$ & $\begin{array}{c}\text { Folliage } \\
\text { ht } \\
(\mathrm{cm})\end{array}$ & $\begin{array}{l}\text { Head } \\
\text { length } \\
(\mathrm{cm})\end{array}$ & $\begin{array}{l}\text { Head : } \\
\text { total ht } \\
\text { ratio }\end{array}$ & $\begin{array}{c}\text { Internode } \\
\text { length } \\
(\mathrm{cm})\end{array}$ & $\begin{array}{l}\text { Head } \\
\text { wt }(\mathrm{g})\end{array}$ \\
\hline \multicolumn{8}{|c|}{$H S 110 \times$ S366, 1989} \\
\hline PT (HS110) & 21 & $49 \pm 0.1$ & $27 \pm 0.8$ & $22 \pm 0.9$ & () $.45 \pm 0.015$ & $2.0 \pm 0.04$ & \\
\hline PS (S366) & 65 & $47 \pm 0.5$ & $21 \pm 0.3$ & $26 \pm 0.4$ & $0.56 \pm 0.005$ & $1.1+0.02$ & \\
\hline $\mathrm{F} 1$ & 144 & $50 \pm 0.5$ & $23 \pm 0.3$ & $27 \pm 0.4$ & $0.54 \pm 0.004$ & $1.6 \pm 0.02$ & \\
\hline $\mathrm{F} 2$ & 339 & $50 \pm 0.3$ & $28 \pm 0.2$ & $27 \pm 0.2$ & () $.54 \pm 0.003$ & $1.5 \pm 0.01$ & \\
\hline BCT & 230 & $49 \pm 0.4$ & $26 \pm 0.2$ & $24 \pm 0.3$ & $0.48 \pm 0.004$ & $1.8 \pm 0.02$ & \\
\hline $\mathrm{BCS}$ & 277 & $49 \pm 0.4$ & $21 \pm 0.2$ & $28 \pm 0.2$ & $0.57 \pm 0.003$ & $1.3 \pm 0.01$ & \\
\hline $\operatorname{LSD}(P=0.05)$ & & 2 & 1 & 2 & 0.02 & 0.07 & \\
\hline \multicolumn{8}{|c|}{$H S 179 \times S 240,1992$} \\
\hline PT (HS179) & 60 & $72 \pm 0.7$ & $32 \pm 0.6$ & $40 \pm 0.6$ & $0,56 \pm 0.006$ & $1.6 \pm 0.03$ & \\
\hline PS (S240) & 73 & $52 \pm 0.4$ & $26 \pm 0.4$ & $26 \pm 0.3$ & $0.50 \pm 0.005$ & $1.3 \pm 0.02$ & \\
\hline $\mathrm{F}_{1}$ & 114 & $64 \pm 0.5$ & $31 \pm 0.4$ & $33 \pm 0.3$ & $0.52 \pm 0.004$ & $1.5 \pm 0.02$ & \\
\hline $\mathrm{F} 2$ & 434 & $59 \pm 0.3$ & $28 \pm 0.2$ & $31 \pm 0.2$ & $0.53 \pm 0.002$ & $1.4 \pm 0.01$ & \\
\hline BCT & 296 & $69 \pm 0.4$ & $32 \pm 0.3$ & $36 \pm 0.3$ & () $.52 \pm 0.002$ & $1.6 \pm 0.01$ & \\
\hline $\mathrm{BCS}$ & 266 & $56 \pm 0.3$ & $27 \pm 0.2$ & $29 \pm 0.2$ & $0.52 \pm 0.003$ & $1.4 \pm 0.01$ & \\
\hline $\operatorname{LSD}(P=0.05)$ & & 2 & 1 & 2 & 0.2 & 0.08 & \\
\hline \multicolumn{8}{|c|}{$H S 179 \times$ S366, 1992} \\
\hline PT (HS179) & 62 & $51 \pm 0.8$ & $29 \pm 0.4$ & $22 \pm 0.6$ & $0.43 \pm 0.006$ & $1.3 \pm 0.01$ & $99 \pm 4.0$ \\
\hline PS (S366) & 26 & $39 \pm 0.9$ & $21 \pm 0.7$ & $18 \pm 0.5$ & $0.46 \pm 0.012$ & $1.0 \pm 0.02$ & $299 \pm 28.0$ \\
\hline $\mathrm{F}_{1}$ & 118 & $47 \pm 0.3$ & $26 \pm 0.2$ & $21 \pm 0.3$ & $0.45 \pm 0.005$ & $1.2 \pm 0.01$ & $228 \pm 8.3$ \\
\hline $\mathrm{F}_{2}$ & 271 & $46 \pm 0.3$ & $25 \pm 0.2$ & $21 \pm 0.2$ & $0.45 \pm 0.004$ & $1.1 \pm 0.01$ & $221 \pm 6.4$ \\
\hline $\mathrm{BCT}$ & 277 & $52 \pm 0.4$ & $29 \pm 0.2$ & $23 \pm 0.3$ & $0.44 \pm 0.004$ & $1.3 \pm 0.01$ & $199 \pm 5.4$ \\
\hline $\mathrm{BCS}$ & 286 & $42 \pm 0.3$ & $22 \pm 0.2$ & $20 \pm 0.2$ & $0.46 \pm 0.004$ & $1.1 \pm 0.01$ & $304 \pm 7.2$ \\
\hline $\operatorname{LSD}(P=0.05)$ & & 3 & 2 & 2 & 0.03 & 0.7 & 80 \\
\hline
\end{tabular}

${ }^{7}$ Generation means derived from total populations (N); LSD derived from means of four replications.

${ }^{y} \mathrm{PT}=$ tall (exserted) parent, PS = short (nonexserted) parent, BCS and BCT = backcrosses of $\mathrm{F}_{1}$ with respective parent. 
the nodes of the foliar portion of the plant were counted. In 1992. the procedures were the same as in 1989 except that measurements were made when the heads were subjectively determined to be commercially mature, based on tightness of the heads as well as floret size and appearance. Additionally, in 1992, the head was cut from each plant, trimmed to $16 \mathrm{~cm}$, and individually weighed. The differentiation of foliage leaves from head leaves or bracts, and determination of commercial maturity in 1992 were crucial and were done by the same person throughout the study.

Because data from reciprocal $\mathrm{F}_{1}, \mathrm{~F}_{2}$, and backcross populations were usually very similar, they were combined. In one case, the data for head weight in the $\mathrm{F}_{2}$ of HS179 $\mathrm{H}$ S366, reciprocal differences were significant. However, since this difference was not consistent among the replications and had no impact on the information derived, these reciprocals were also combined.

Gene effects were estimated by means of a three-parameter jointscaling test adapted by Rowe and Alexander (1980) from a method described by Cavalli (1952) and illustrated by Mather and Jinks (1971). The test involves weightext least squares where the weights are the reciprocals of the standard errors of the generation rneans.

\section{Results and Discussion}

Differences in the characteristic we have described as head exsertion in broccoli inbred lines could not generally be related to differences in plant proportions. The mean head length: total plant height ratio in the six generations ranged from $\approx 0.45$ to 0.55 , but within individual crosses was more uniform among the generations (Table 1). In HS179 x S240, the exserted parent (PT) had a head : total ratio greater than that of the nonexserted parent (PS), but in HS110 x S366, PS (S366) had ahead: total ratio significantly greater than that of PT (HS110). These differences may be largely due to differences in plant form among the parents, but may have been partly related to our procedure in 1989 in which measurements were not taken until a flower opened. This delay appeared to allow the head : total ratio to increase and may have resulted in a differential increase between HS110 and S366. Mean head: total height ratios for HS179 x S366 in 1992, where measurements were taken at commercial head maturity, were uniformly near 0.45 . A comparison of the three crosses, confounded by the comparison of years, suggests that HS179 and S366 as parents contribute greater
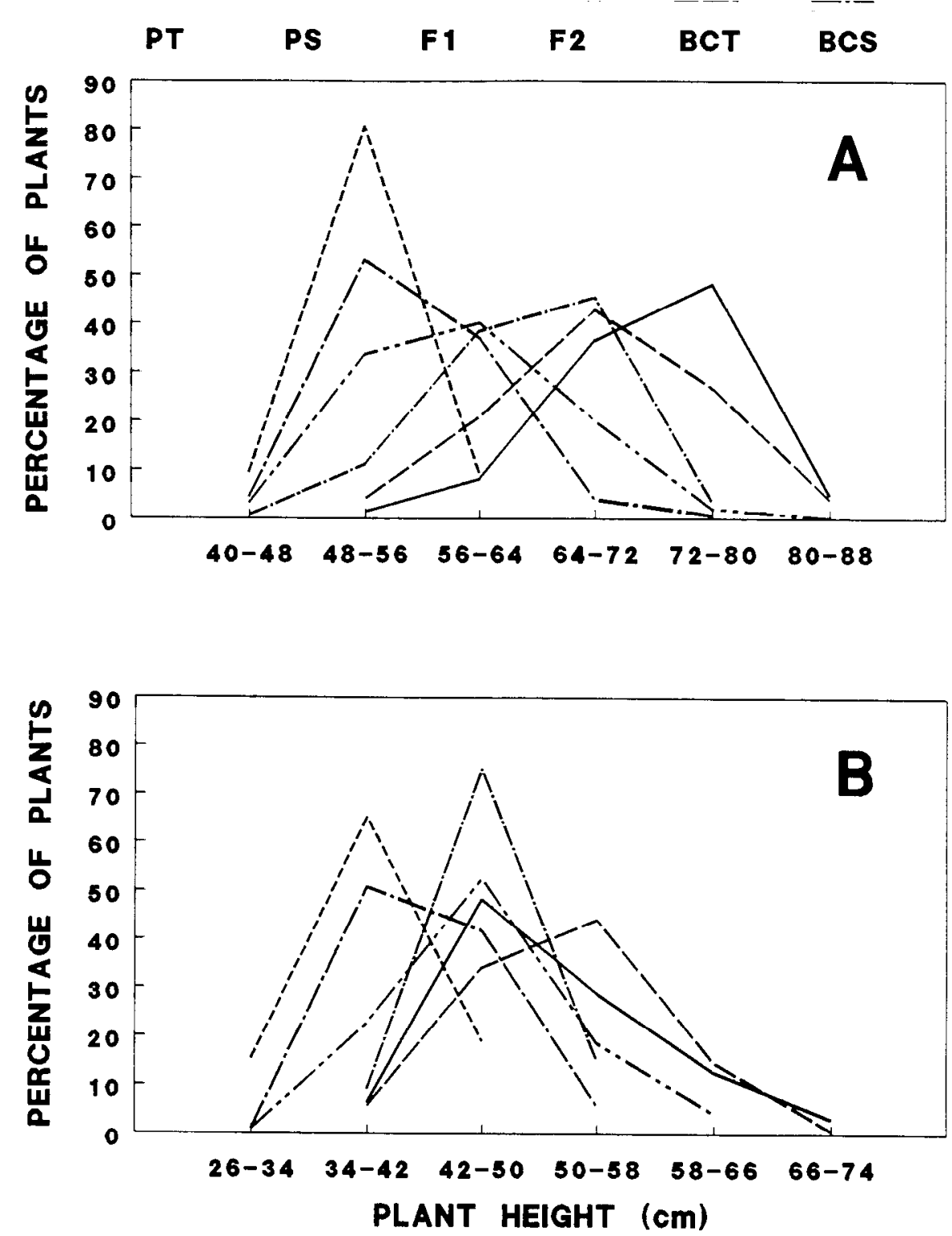

Fig. 3. Frequency distribution of plant height of individual plants in generations of (A) HS179 x S240 and (B) HS179 x S366. 
head : total ratios than HS110 and S240.

The rather constant relationship between head length and total plant height agrees with the results of Walton and Casada (1988).

Plant height. Although $\mathrm{F}$ values for plant height were significant at 0.05 probability in all three crosses, the difference between HS110 and S366 was small and plant height among the progeny generations was almost identical in this cross (Table 1). Although we had considered HS110 and HS179 to be of the exserted type, the mean total height of HS179 was $71.5 \mathrm{~cm}$ compared to only $49.2 \mathrm{~cm}$ for HS110. Both crosses involving HS179 showed conspicuous differences among parents and progeny generations. Although overall height in 1989 was greater than in 1992, due to time of measurement and because all plants were more vigorous in 1989, proportional differences among generations were similar in HS179 x S240 (1989) and HS179 x S366 (1992). The relationship among generation means indicated that plant height is additive in inheritance, but with some dominance or heterosis for greater height suggested by the similarity of PT and BC, and the slightly greater height of the $F_{1}$ compared to the $F_{2}$. Frequency distributions of plant height in individual plants of-the generations of HS179 x S240 and HS179 x S366 (Fig. 3) generally supported the generation means data (Table 1) in indicating that inheritance of total height was additive. In HS179 x S366 there was some apparent heterosis expressed in BCT compared to PT.

Internode length. Total height is a practical Factor involved in head exsertion because it affects ease of harvest. However, difference in internode length between the high and low exsertion parents is more pronounced and maybe more important because it relates to the possibilities of harvesting heads which are free from leaves and low in fiber. In all three crosses, internode length of PT was substantially greater than in PS (Table 1). HS110, which was only $5 \%$ greater in mean height than $\mathrm{S} 366$, was $75 \%$ greater in internode length. HS179 was $26 \%$ and $32 \%$ greater in internode length than S240 and S366, respectively.

Table 2. Estimates of gene effects for internode length using joint scaling tests of generation means.

\begin{tabular}{|c|c|c|c|c|c|}
\hline \multirow[b]{2}{*}{ Cross } & \multicolumn{3}{|c|}{ Gene effects } & \multirow[b]{2}{*}{ Chi-square } & \multirow[b]{2}{*}{$P$} \\
\hline & Mean $(\mathrm{cm})$ & Additive & Dominance & & \\
\hline HS110 x S366 & $1.56 \pm 0.047$ & $0.465 \pm 0.046$ & $-0.059 \pm 0.076$ & 26.7 & $<0.001$ \\
\hline $\mathrm{HS} 179 \times \mathrm{S} 240$ & $1.47 \pm 0.043$ & $0.200 \pm 0.040$ & $0.047 \pm 0.077$ & 27.8 & $<0.001$ \\
\hline HS179 x S366 & $1.12 \pm 0.006$ & $0.181 \pm 0.007$ & $0.087 \pm 0.014$ & 14.6 & $<0.01$ \\
\hline
\end{tabular}

Table 3. Frequency distribution (percentage of plants) for internode length in HS110 x S366.

\begin{tabular}{|c|c|c|c|c|c|c|}
\hline \multirow[b]{2}{*}{ Generation $^{2}$} & \multicolumn{6}{|c|}{ Internode length $(\mathrm{cm})$ class } \\
\hline & $0.6-1.0$ & $1.0-1.4$ & $1.4-1.8$ & $1.8-2.2$ & $2.2-2.6$ & $2.6-3.0$ \\
\hline PT & & & 23.8 & 66.7 & 9.5 & \\
\hline PS & 18.5 & 75.4 & 6.2 & & & \\
\hline $\mathrm{F}_{1}$ & & 19.4 & 70.1 & 10.4 & & \\
\hline $\mathrm{F}_{2}$ & & 32.2 & 57.5 & 9.4 & 0.9 & \\
\hline B-CT & & 3.0 & 46.5 & 43.0 & 6.5 & 0.9 \\
\hline BCS & 2.5 & 71.8 & 24.6 & 0.7 & & 0.4 \\
\hline
\end{tabular}

$\overline{{ }^{2} \mathrm{PT}}=$ tall $\left(\right.$ exserted) parent, $\mathrm{PS}=$ short $\left(\right.$ nonexserted) parent, $\mathrm{BCS}$ and $\mathrm{BCT}=$ backcrosses of $\mathrm{F}_{1}$ with respective parent.

Table 4. Frequency distribution (percentage of plants) for internode length in HS179 x S240.

\begin{tabular}{|c|c|c|c|c|c|c|}
\hline$\overline{\mathrm{PT}}$ & & 22.0 & 50.9 & 20.3 & 5.1 & 1.7 \\
\hline $\mathrm{F}_{1}$ & 0.9 & 25.4 & 56.1 & 14.9 & 2.6 & \\
\hline $\mathrm{F}_{2}$ & 5.3 & 45.2 & 35.5 & 11.3 & 2.5 & 0.2 \\
\hline $\mathrm{BCT}$ & 0.7 & 18.6 & 46.0 & 27.0 & 6.8 & 1.1 \\
\hline
\end{tabular}

${ }^{2} \mathrm{PT}=$ tall $\left(\right.$ exserted) parent, $\mathrm{PS}=$ short (nonexserted) parent, $\mathrm{BCS}$ and $\mathrm{BCT}=$ backcrosses of $\mathrm{F}_{1}$ with respective parent.

Table 5. Frequency distribution (percentage of plants) for internode length in HS179 x S366.

\begin{tabular}{|c|c|c|c|c|c|c|}
\hline Generation' & \multicolumn{6}{|c|}{ Internode length $(\mathrm{cm})$ class } \\
\hline PT & & 4.8 & 80.6 & 14.5 & & \\
\hline $\mathrm{F}$ & & 21.2 & 75.4 & 3.4 & & \\
\hline $\mathrm{F}_{2}$ & 0.7 & 40.2 & 53.9 & 4.8 & & 0.4 \\
\hline $\mathrm{BCT}$ & & 13.7 & 67.9 & 18.0 & 0.4 & \\
\hline
\end{tabular}

${ }^{2} \mathrm{PT}=$ tall (exserted) parent, $\mathrm{PS}=$ short (nonexserted) parent, $\mathrm{BCS}$ and $\mathrm{BCT}=$ backcrosses of $\mathrm{F}_{1}$ with respective parent. 


\begin{tabular}{|c|c|c|c|c|c|c|c|c|}
\hline \multirow[b]{3}{*}{ Character } & \multirow[b]{3}{*}{ Class } & \multicolumn{6}{|c|}{ Mean head weight $(g)^{z}$} & \multirow{3}{*}{$\begin{array}{c}\text { Generations } \\
\text { combined }\end{array}$} \\
\hline & & \multicolumn{6}{|c|}{ Generation } & \\
\hline & & PT & PS & $F_{1}$ & $\mathrm{~F}_{2}$ & $\mathrm{BCT}$ & $\mathrm{BCS}$ & \\
\hline \multirow[t]{4}{*}{ Internode length $(\mathrm{cm})$} & $0.7-1.0$ & -- & $285(14)$ & $153(4)$ & $262(52)$ & $172(7)$ & $306(132)$ & $286(209)$ \\
\hline & $1.0-1.3$ & $96(37)$ & $314(12)$ & $226(91)$ & $220(177)$ & $202(151)$ & $307(148)$ & $232(616)$ \\
\hline & $1.3-1.6$ & $104(25)$ & --- & $250(23)$ & $177(40)$ & $201(110)$ & $212(6)$ & $190(204)$ \\
\hline & $1.6-1.9$ & --- & --- & --- & $114(1)$ & $144(9)$ & --- & $141(10)$ \\
\hline \multirow[t]{4}{*}{ Plant height $(\mathrm{cm})$} & $28-39$ & $91(1)$ & $209(10)$ & $79(2)$ & $180(27)$ & $106(6)$ & $218(61)$ & $198(107)$ \\
\hline & $39-50$ & $82(33)$ & $355(16)$ & $219(98)$ & $222(181)$ & $171(105)$ & $322(208)$ & $242(641)$ \\
\hline & $50-61$ & $118(25)$ & --- & $295(18)$ & $234(60)$ & $219(153)$ & $394(17)$ & $229(273)$ \\
\hline & $61-72$ & $129(3)$ & --- & -- & $235(3)$ & $230(113)$ & --- & $215(119)$ \\
\hline
\end{tabular}

${ }^{2}$ Mean head weight of plants in the respective class for internode length or plant height. Numbers in parentheses are the number of individual plants measured. Heads were cut to a uniform length of $16 \mathrm{~cm}$.

The relationship of the generation means for HS 110 x S366 was nearly perfect for supporting additive inheritance of internode length (Table 1). In both crosses involving HS179, a similar additive pattern was apparent among BCT, $\mathrm{F}_{1}-\mathrm{F}_{2}, \mathrm{BCS}$, and PS, but the relationship between PT and BCT suggested dominance of long internode or that internode length in BCT was affected by hybrid vigor. In all three crosses, the $\mathrm{F}_{1}$ had slightly greater mean internode length than that of the $F_{2}$, suggesting a degree of heterosis. A generation means analysis (Table 2) for internode length showed that additive gene effects were much more important than dominance effects and supported the conclusions drawn from Table 1.

Frequency distributions of internode length in individual plants (Tables 3-5) generally supported the information provided by generation means, but the broad distributions, even in parents and $\mathrm{F}$, tended to obscure comparisons among the generations. As with generation means, frequency distributions more clearly indicated additive inheritance in HS 110 x S366 (Table 3) than in HS $179 x$ S240 (Table 4) or HS 179 x S366 (Table 5). In the latter crosses, with the six-interval frequency distributions used, PT, $\mathrm{F}_{1}$, and BCT peaked in the same internode length class, and PS and BCS peaked in the same class. The $\mathrm{F}_{2}$ was broader in distribution, but peaked with PS in HS $179 \times$ S240 and with PT in HS 179 x S366. Frequency distributions did not contradict a hypothesis that the inheritance of internode length is quantitative and additive in nature. These results generally agree with those of a previous study of internode length in crosses between broccoli and cabbage (Pelofske and Baggett, 1979).

Relationship between head weight and head exsertion components. Individual plant variation in weight of heads cut to a length of $16 \mathrm{~cm}$ was high in HS179 x S366, but the analysis of variance using replication means produced an $\mathrm{F}$ value for generations significant at 0.01 probability. Most comparisons among generations were nonsignificant. However, the mean head weight of 99 $\mathrm{g}$ for PT differed significantly from the weight of $299 \mathrm{~g}$ for PS. No attempt was made to derive genetic information from these data, except to note that the pattern suggested mostly additive inheritance with the parents being lower than expected, presumably because of inbreeding depression.

Overall, head weight was negatively associated with internode length. A correlation of $r=-0.33$ was obtained from head weight vs. internode length when all individual plants of all generations were combined. Mean head weights derived from individual plants in internode length and plant height frequency distribution classes are shown in Table 6. Head weight decreased with increasing internode length when all plants were combined. In PT, PS, and $\mathrm{F}_{1}$ (the genetically uniform populations), plants with longer intern- odes (larger plants) had greater head weight. In the $\mathrm{F}_{2}$, longer internodes were associated with smaller heads, and this trend tended to be the case in the backcrosses, although the trend was not consistent. Thus, selection for long internodes in $\mathrm{F}_{2}$ populations would tend to result in selection for lower head weight, and this has been our experience. When the $\mathrm{F}_{2}$ data shown in Table 6 were tabulated with four head weight classes under each internode length class, there were no heads weighing $>410 \mathrm{~g}$ in the plants with internode length over $1.3 \mathrm{~cm}$. In plants with internode length from 0.7 to $1.3 \mathrm{~cm}, 7 \%(15 / 229)$ had heads weighing $>410$ grams. Thus, with the number of $\mathrm{F}_{2}$ plants we studied, recovery of plants with heavier heads and long internodes was not possible. In a similar tabulation of the $\mathrm{F}_{2}$ for plant height, there were $6 / 63$ heads weighing $>410$ grams in the 50 to $61 \mathrm{~cm}$ height class, and none in the 61 to 72 height class. It appears necessary to choose parents for $F_{1}$ hybrids or development of new inbred lines that will increase overall plant and head size to improve chances for obtaining exserted lines or hybrids with acceptable yield.

Head size means for plant height frequency distribution intervals for all plants and within generations indicate that head weight increases with plant height, even though the correlation between plant height vs. head weight was essentially zero $(r=-0.006)$. Although taller plants would tend to have longer internodes, the association between height and plant bulk or size per se apparently negated the tendency for longer internode genotype to be associated with smaller heads. Head and stem diameter were not measured in this study. An apparent negative relationship between stem diameter, head diameter. and head weight should be studied in future research.

\section{Literature Cited}

Baggett, J.R. and D. Kean. 1985. Broccoli breeding lines OSU 101-115. HortScience 20:782-784.

Casada, J.H., L.R. Walton, and M.J. Bader. 1989. Single pass harvesting of broccoli. Applied Eng. Agr. 5(4):463-466.

Cavalli, L. 1952. An analyses of linkage in quantitative inheritance, p. 135-144. In: E.C.R. Reeve and C.H. Waddington (eds.). Quantitative inheritance. HMSO, London.

Mather, K. and J.L. Jinks. 1971. Biometrical genetics. The study of continuous variation. Cornell Univ. Press, Ithaca, N.Y.

Pelofske, P.J. and J.R. Baggett. 1979. Inheritance of internode length, plant form, and annual habit in a cross of cabbage and broccoli (Brassica oleracea var. Capitata L. and var. italica Plenck.). Euphytica 28: 189-197.

Rowe, K.E. and W.L. Alexander. 1980. Computations for estimating the genetic parameter in joint-scaling tests. Crop Sci. 20:109-1 10.

Walton, L.R. and J.H. Casada. 1988. Evaluation of broccoli varieties for mechanical harvesting. Applied Eng. Agr. 4(1):5-7. 